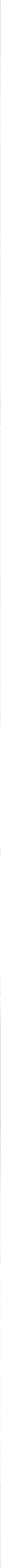




\section{SESC Quitandinha. Petrópolis, Rio de Janeiro}

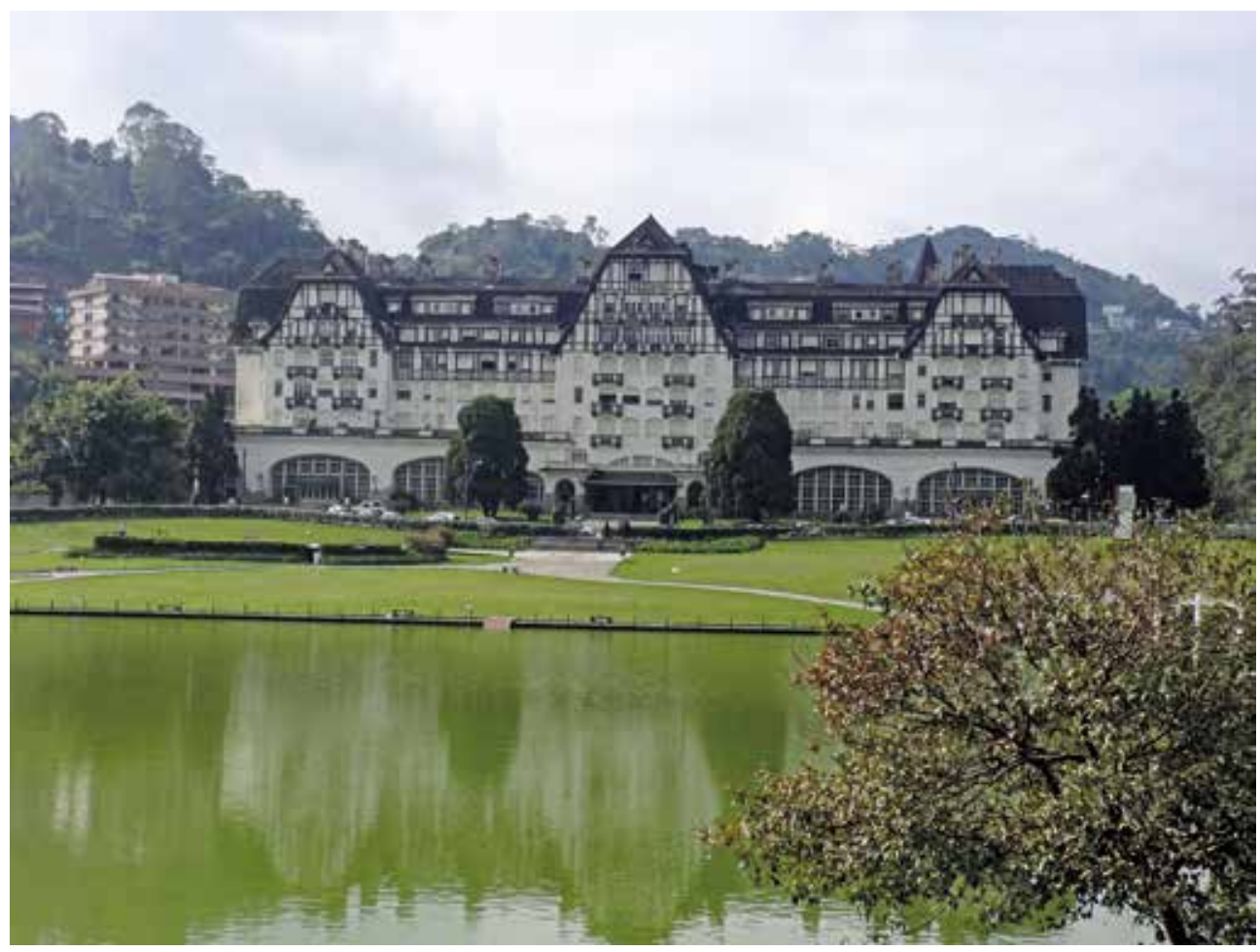

Palacio Quitandinha. Petrópolis

La historia del Palacio Quitandinha merece ser contada, aunque sea, brevemente: Joaquín Rolla, un empresario brasilero propietario de varios casinos, se había propuesto construir en un sector de la antigua hacienda Quitandinha, en Petrópolis, el que sería el casino-hotel más grande de América del Sur. En 1939, adquirió el terreno y en 1941 encargó la construcción de su ambicioso proyecto a los arquitectos Luis Fossati y Alfredo Baeta Neves. El edificio se inauguró en 1944.

Lamentablemente para Rolla, la esposa del presidente de la República del Brasil abogó, con todo éxito, para que las casas de juego fueran proscritas por "inmoralidad". ¿Cómo se sintió el empresario cuando esta censura lo vio obligado a cerrar su casino-hotel en 1946, apenas dos años después de haberlo inaugurado? 


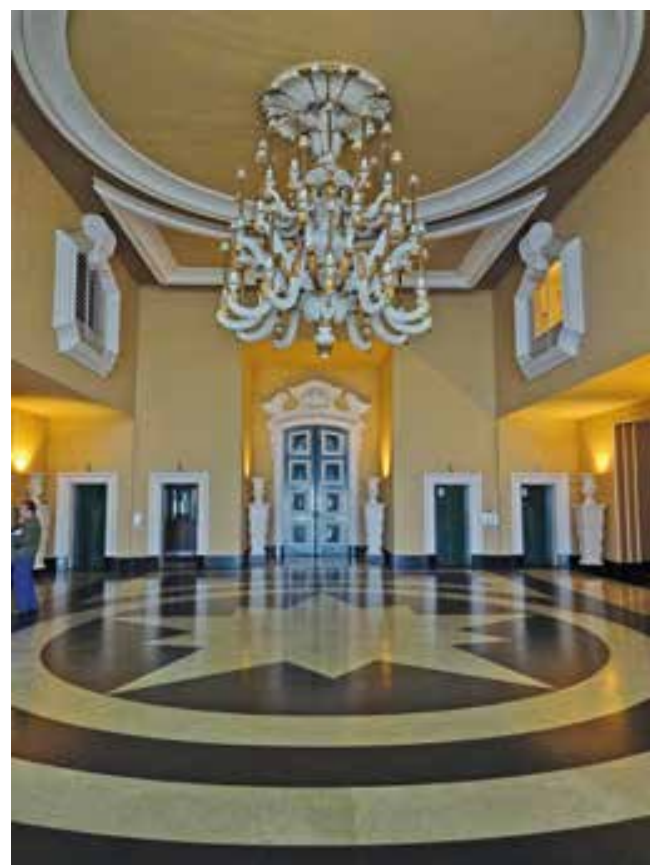

Recepción

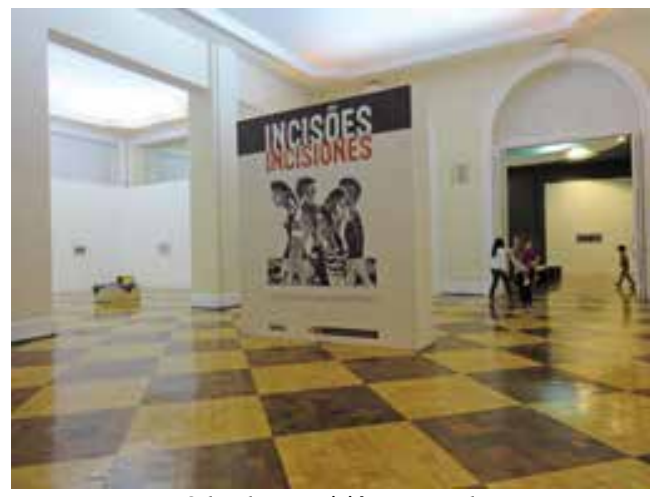

Salas de exposición temporal

Tras este apresurado final, el edificio pasó por todas las experiencias predecibles: fue abandonado y prolijamente despojado de sus muebles y acabados, permaneciendo fuera de servicio y sin rumbo durante un buen tiempo hasta que lo adquirió el SESC, habilitándolo para su uso como centro cultural.

Pero ¿qué es el "SESC"? SESC son las siglas del "Servicio Social de Comercio", una institución brasilera privada, sin fines lucrativos, sostenida por los empresarios del comercio de bienes, servicios y turismo, con acción a nivel nacional, dirigido principalmente para el bienestar social de sus empleados y familiares y a la comunidad en general. Desarrolla actividad en las áreas de Educación, Salud, Entretenimiento, Cultura y Asistencia. Fue creado el 13 de septiembre de 1946 por Decreto Ley No9853, cuando el Presidente Eurico Gaspar Dutra autoriza a la Confederación Nacional de Comercio para la creación del Servicio Social de Comercio. La sede del Departamento Nacional del SESC está localizado en la ciudad de Rio de Janeiro, en Jacarepaguá1.

Tuvimos la oportunidad de conocer el SESC Quitandinha y ver su óptimo funcionamiento como centro cultural cuando llevamos allí la exposición grupal INCISIONES. Xilografía peruana contemporánea que permaneció abierta al público entre el 28 de agosto y el 18 de octubre de $2015^{2}$.

Dio la casualidad de que Carlos Bernasconi, uno de los grabadores peruanos participantes, conoció el Palacio Quitandinha en 1950, cuando, a pesar de llevar desactivado casi un lustro, era considerado todavía uno de los hoteles más grandes del mundo. En verdad, la edificación impresiona tanto por la escala monumental de su denominado "estilo normando" como por su ubicación en medio de la vegetación montañosa de Petrópolis, la ciudad real creada en honor al Emperador Pedro II. Petrópolis, que fue la capital oficial del Estado de Rio de Janeiro entre 1894 y 1902, está situada a casi mil metros sobre el nivel del mar, lo que la convirtió en la comarca ideal para que la familia real huyera de los sofocantes veranos en Rio de Janeiro, situada apenas a 68 kilómetros de allí.

1 Información proporcionada en el portal web del SESC Quitandinha. Consulta realizada en noviembre de 2015.

2 INCISIONES se expuso en tres salas del Brasil durante el año 2014: en la "Casa de la Xilografía", Campos do Jordao (marzo-mayo); en el Instituto Cervantes de Sao Paulo (julio-agosto) y en el Instituto Cervantes de Rio de Janeiro (octubre-noviembre). Los grabadores representados son Carlos Bernasconi, Félix Rebolledo, Alberto Ramos, Martín Moratillo, Marco Alburqueque, Israel Tolentino y Luis Torres. 
El equilibrio funcional que se ha conseguido en este lugar merece ser destacado: todos los departamentos del antiguo hotel están habitados por una población estable, mientras que las áreas comunes del primer nivel constituyen el circuito cultural que incluye varias salas para exhibiciones de artes visuales, salas de conferencia, un teatro con capacidad para más de mil personas -cuyo escenario giratorio se descalabró cuando subieron a un elefante- y una boite que parece arrancada de una película de la Paramount. "Tienes razón”, me dijo el guía, "quien la diseñó era una escenógrafa de Hollywood". Adicionalmente ofrece una gran pista de patinaje sobre hielo -por ahora fuera de servicio- y un boliche.

Paralelamente existe un circuito que recorre las antiguas instalaciones del hotel entre las que destaca la sala destinada a los periodistas, colmada de elegantes pupitres, cada cual provisto de una conexión telefónica, así como la cocina cuya enorme escala le permitió, en sus mejores tiempos, servir hasta diez mil platos diarios. Los escombros de la enorme batidora dan una idea del trajín del regimiento de cocineros que allí trabajó.

Este monumental edificio, ubicado al ingreso de la ciudad, se ha convertido también en uno de sus principales atractivos y es, sin duda, su imagen emblemática. Durante los días que por allí anduvimos, circularon varias parejas de novios y varias promociones de escolares con togas que usaban su fachada y su laguna artificial -la cual tiene la forma del mapa de Brasil- como locaciones para las correspondientes sesiones fotográficas.

Mientras caminábamos por los salones del SESC Quitandinha y visitábamos las demás exposiciones, no podíamos dejar de lamentar la destrucción de la Casa Marsano en Miraflores, a mediados del año

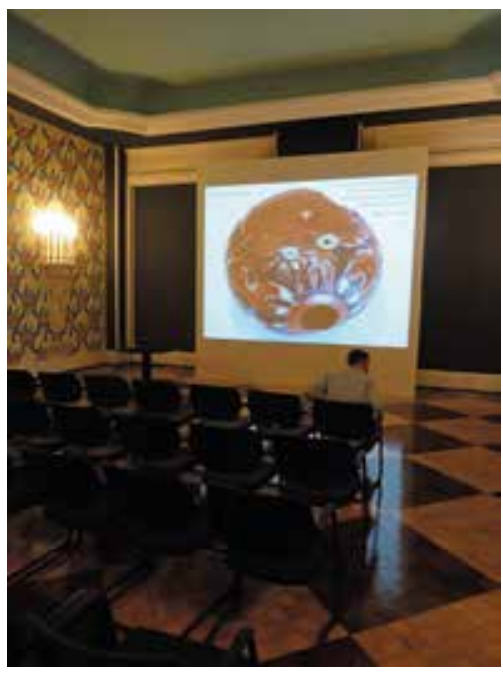

Sala de conferencias

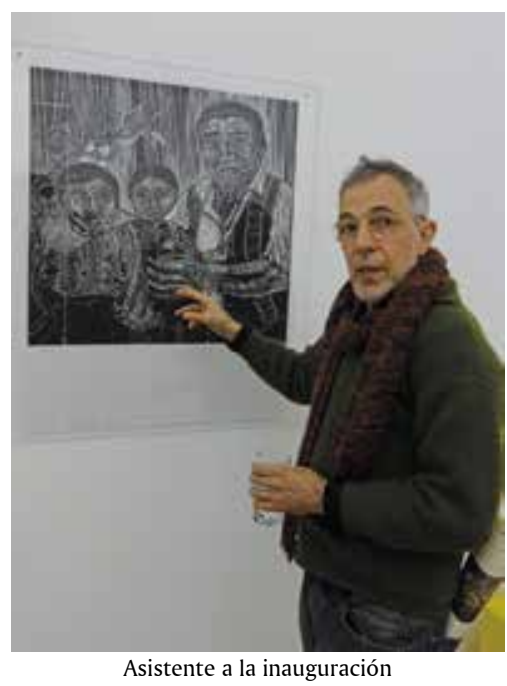
2002, inmediatamente después de que sus propietarios se enteraran de que existía la posibilidad de que fuera declarada "monumento histórico". Qué estupendo museo de arte se habría podido montar allí. Nos habría librado, además, de la deleznable construcción que afea esa cuadra de la Av. Arequipa y que nos duele todavía a quienes recordamos la monumentalidad del palacete derruido. 